\title{
ЦИФРОВАЯ ТРАНСФОРМАЦИЯ ОРГАНИЗАЦИЙ В СОВРЕМЕННЫХ РОССИЙСКИХ УСЛОВИЯХ
}

\section{DIGITAL TRANSFORMATION OF ORGANIZATIONS IN MODERN RUSSIAN CONDITIONS}

\section{N. Vnukovsky A. Kolyshev}

Summary. The article deals with the popular issues of digitalization that underlie the business processes of enterprises and corporations. The most significant problems of digital transformation of companies in Russian conditions are emphasized.

Keywords: digitalization, digital transformation, personnel policy, digital competencies, digital economy, innovative business modeling, startup studios, educational environment.
B современных условиях, связанных с пандемией, с понижением уровня жизни народа и снижением темпов роста экономики страны, произошли существенные изменения в развитии человеческих отношений. Например, резкий скачок развития и распространения информационных технологий привело к интенсивному развитию и внедрению цифровых технологий во всех сферах человеческой деятельности. На предприятиях и в отношениях между людьми возникают новые отношения на базе совершенствования бизнес-процессов и операций на основе цифровой трансформации путем применения современных технологий для повышения конкурентоспособности предприятий, как гибкое реагирование предприятий на внешнее изменение.

Такими изменениями на платформе цифровизации являются резкое увеличение социальных сетей, широкий доступ к интернету, всеобщая компьютеризация и развитие искусственного интеллекта. Путем цифровизации создаются новые продукты, но уже в цифровом виде, такими продуктами могут быть интерактивные информационные системы для создания какого-либо документа, проекта или в образовательной деятельности - разработка презентационного динамического специального курса обучения и проведения актуальных, востребованных вебинаров для слушателей, персонала. Цифровая трансформация позволяет масштабировать цифровые продукты, в частности, тиражировать разработанные учебные интерактивные курсы
Внуковский Николай Иванович

Д.э.н., профессор, Уральский государственный Университет путей сообщений, г. Екатеринбург

vnukovsk@ya.ru

Колышев Андрей Сергеевич

К.э.н., старший преподаватель, Уральский государственный Университет путей сообщений,

г. Екатеринбург

ASKolyishev@bk.ru

Аннотация. В статье рассмотрены востребованные вопросы цифровизации, которые лежат в основе бизнес-процессов деятельности предприятий и корпораций. Акцентированы наиболее существенные проблемы цифровой трансформации компаний в российских условиях.

Ключевые слова: цифровизация, цифровая трансформация, кадровая политика, цифровые компетенции, цифровая экономика, инновационное бизнес-моделирование, стартап-студии, образовательная среда.

до любого масштаба, при этом затраты сокращаются значительно за счет снижения цены и доступности дружественного цифрового интерфейса. Цифровая трансформация позволяет автоматизировать отдельные бизнес-операции, например, проведение тестирования слушателей для учебного курса $[1,2]$.

Цифровая трансформация позволяет собирать необходимые данные для принятия управленческих решений в on-line режиме. Цифровая трансформация широко используется с использованием интернет вещей, когда многие бытовые приборы позволяют вести удаленное управление за объектами. Также цифровизация позволяет добавлять к объектам реального мира виртуальные объекты. На базе смартфонов и интернета развивается инструментарий геопозиционирования для нахождения и определения необходимых объектов.

На рынке создаются экосистемы, в которых работают сервисы на основе искусственного интеллекта, в них заложены элементы систем знаний, алгоритмы поиска оптимальных и правильных решений в неопределенных ситуациях, например, в постановке врачебных диагнозов сложных заболеваний. В этом случае разрабатываются сложные интеллектуальные системы на базе искусственного интеллекта. За счет искусственного интеллекта многие специальности могут быть замещены, робототехника придет в реальную жизнь, что уменьшит количество ошибок и время их исполнения $[3,5]$. 
Следует отметить, что в цифровой трансформации важен совокупный синергетический эффект за счет взаимодействия различных цифровых технологий на существующие бизнес-процессы, и как результат, в компании происходят постоянные изменения различных операций, процессов, и даже сама социальная система также находится в постоянном качественном изменении, задавая для предприятий и всего персонала траекторию дальнейшего развития [4].

Цифровая трансформация приведет к изменениям во всех отраслях, появятся много новых предприятий и компаний. При этих изменениях возникает проблема о трансформировании больших организаций и корпораций, которые являются консервативными, бюрократическими, и стратегический уровень управления оказывает наибольшее сопротивление цифровой трансформации. Так, например, железнодорожные компании находятся на начальном этапе цифровой трансформации [3-4].

Рекомендуется таким организациям для старта цифровой трансформации создавать инновационные стартап-студии, которые будут проектировать новые бизнес-модели в профессиональной деятельности на основе цифровых технологий. Такого рода инновационные подразделения обычно создаются на базе IT-подразделений, либо рядом с ними.

Проанализируем особенности цифровой трансформации компаний в российских условиях. Существует множество кейсов из практики цифровой трансформации, но все они разработаны на опыте зарубежных предприятий, которые не всегда подходят для российского менталитета. В государственных компаниях в России внедрение цифровых технологий происходит медленными темпами и креативность цифровой трансформации проявляется в коммерческих российских компаниях среднего размера. Это предприятия в телекоммуникациях и банковском секторе. Однако они работают с определенной степенью риска, не имея возможности конкурировать с иностранными компаниями.

В то время как в компаниях и на предприятиях за рубежом существует целая экосистема стартапов, где возникают новые идеи, которые после лабораторных исследований могут стать инновационными коммерческими решениями для возникающих проблемных вопросов и в дальнейшем находят спрос на рынке. На российском рынке в основном занимаются реинжинирингом бизнес-процессов, понимая, что иначе при создавшейся конкуренции не выжить. Российские предприятия и крупные компании, корпорации еще не поняли значимости цифровой трансформации и не- обходимости ее применения с целью повышения конкурентоспособности и ценности своего предприятия.

Уже сегодня, всем понятно, что зарождается новая цифровая экономика: цифровизация - это реальность, создаются цифровые экосистемы во многих сферах деятельности - в торговле, в банках, в авиации и т.д. Цифровизация имеет глобальные масштабы, постепенно вся наша деятельность и дома и на работе будет связана с цифровыми экосистемами, появятся технологии персонифицирования - оказание нужных предложений для своих клиентов в нужное время и в нужном месте, компании с помощью персональных настроек будут таргетировать предложения с точностью до конкретного потребителя.

Естественно, при цифровой трансформации сократится время на коммуникации, ускорятся все процессы экономической и производственной деятельности, но что будет с экономикой России, которая за последние 20 лет оказалась «замороженной» в силу многих объективных и субъективных факторов. Цифровая трансформация экономики приведет к существенным изменениям на предприятиях, в бизнесе, в отношениях между людьми, а также в управлении персоналом [5].

По этой причине именно дефицит компетентных кадров следует снизить путем обучения, переквалификации и адаптации на местах с активным использованием цифровой трансформации на предприятиях.

На современном этапе меняется понятие и смысл профессионального образования, встает вопрос о переходе к новой терминологии, отражающей существенные изменения в самом его содержании. Необходимо не просто «знать», а главное «уметь» и приобрести необходимые компетенции, чтобы уметь их применять на практике, тогда и наступают кардинальные изменения в образовательной сфере $[14,16]$.

В период коммерциализации образования качество образования стало резко падать по многим причинам (отношения, престиж, мотивация и т.д.). Сегодня в связи с развитием цифровой трансформации требуется реструктуризация и изменение системы образования, поскольку в бизнесе в основе лежат человеческие отношения и наибольшие успехи у персонала происходят за счет компетенций «уметь» и «владеть». В современных бизнес-моделях постоянно меняются навыки в компетенциях, что определяется требованиями к новым специальностям и профессиям.

Таким образом, важным аспектом в развитии цифровой трансформации является вопрос формирования образовательной среды цифровой экономики. В настоящий 
момент, в эпоху переходного периода цифровизации, перед университетами будут стоять следующие задачи [11]:

1. Расширить нишу учебных программ, сделав упор на программы, где студенты будут осваивать знания и умения, требуемые цифровой экономикой.

2. Формировать образовательную среду, способную гибко реагировать на изменения окружающей среды и на требования цифровой трансформации в различных сферах деятельности.

3. Создать Центр подготовки кадров по кибербезопасности, Центр блокчейна и креативных индустрий на базе цифровой трансформации.
Цифровая трансформация существенно изменит способы предоставления и получения образовательных процессов, но здесь много проблем: неравенство доступа к цифровым технологиям, снижение качества образования из-за различных причин, связанных с его коммерциализацией. Тем более необходимо отметить, что современные информационно-коммуникативные технологии на основе цифровой трансформации могут применяться для повышения эффективности образовательного процесса, а также улучшения качества обучения, поскольку образование имеет ведущую роль в развитии современного общества $[13,16]$.

\section{ЛИТЕРАТУРА}

1. Беликова К.М. Цифровая интеллектуальная экономика: понятие и особенности правового регулирования (теоретический аспект) / К.М. Беликова // Наука и образование: хозяйство и экономика; предпринимательство; право и управление.— 2018. — № 8 (99). C. — 82-85.— https://elibrary.ru/ item.asp?id=35330055.

2. Введение в «Цифровую» экономику/ А.В. Кешелава, В.Г. Буданов, В.Ю. Румянцев и др.; под общ. ред. А.B. Keшелава, http://spkurdyumov.ru/ uploads/2017/07/vvedenie-v-cifrovuyu-ekonomiku-na-poroge -cifrovogo-budushhego.pdf.

3. Внуковский Н.И. Тенденции трансформации корпораций с целью повышения их конкурентоспособности // Современная наука: актуальные проблемы теории и практики. Серия «Экономика и право» № 12/2.-2017. - С. 4-8.

4. Внуковский Н.И. Интеллектуально-организационные проблемы в развитии интеллектуальной транспортной системы // Современная наука: актуальные проблемы теории и практики. Серия: Экономика и право. -2020 — № 1.—C. 16-20.

5. Куприянов Ю. Цифровая трансформация и экспоненциальные технологии как основа для новых моделей бизнеса. Презентация. [Электронный источник] URL: https://bi.hse.ru/data/2017/03/31/1168546830/KC28.03\%20.pdf (Дата обращения: 01.06.2020 г.).

6. Официальный сайт Министерства экономического развития Российской Федерации. 18.12.17. [Электронный источник] URL: http://economy.gov.ru/ minec/press/news/2017181201 (Дата обращения: 02.06. 2020 г.).

7. Минасян Л. А., Казьмина Л.Н., Бадальянц С.В., Бородай В.А., Дудкина О.В. Монография «Развитие цифровой экономики в России как ключевой фактор экономического роста и повышения качества жизни населения». 2019 г.

8. Росляков А.В., Ваняшин С.В., Гребешков А.Ю., Самсонов М.Ю. Интернет вещей. Под ред. А.В. Рослякова. — Самара: ИУНЛ ПГУТИ, 2014. — 340 С.

9. Давыденко Е.А. Эволюция концепции сбалансированной системы показателей: от истоков к цифровому предприятию / Е.А. Давыденко // Российское предпринимательство. — 2018. — Том 19, № 2.—C. 457-472. — doi: 10.18334/rp.19.2.38773 https://creativeconomy.ru/lib/38773.

10. Дятлов, С.А. Технология блокчейн как цифровая платформа для развития институтов электронного правительства [Текст] / С.А. Дятлов, 0.С. Лобанов // Инновации. - 2018. - № 9.- С. 20-28.

11. Киреев В.С. Исследование особенностей применения беспроводных технологий в электронной коммерции [Электронный ресурс] / В.С. Киреев, В.Ю. Крышкова // Теория. Практика. Инновации. — 2018. — № 4.— http://www.tpinauka.ru/2018/04/Kireev2.pdf.

12. Краснушкина М. Цифровое образование выводят в массы. Растить новые кадры будут технологично / М. Краснушкина // Коммерсантъ. - 2018. 20 дек. - https://www.kommersant.ru/doc/3835904.

13. Осипов В.С. Политика цифровизации: необходимость защиты живого труда / В.С. Осипов // Интеллект. Инновации. Инвестиции. — 2018. — № 6. C. 42-46. https://elibrary.ru/item.asp?id=36295484.

14. Панкратов И.Ю. Цифровое государство: новая матрица компетенций для цифровой трансформации / И.Ю. Панкратов, Н.В. Свертилова, Е.Н. Лидэ // Государственная служба. - 2018. - № 1.- С. 38-43.

15. Развитие цифровой экономики в России. Программа до 2035 года. http://innclub.info/wpcontent/uploads/strategy.pdf [Электронный ресурс].

16. Тебекин А.Б. Проблемы развития высшего образования и науки в условиях формирования цифровой экономики // Журнал педагогических исследований. — 2018. — № 4 - Режим доступа: http://znanium.com/catalog/product/1003689.

( ) Внуковский Николай Иванович (vnukovsk@ya.ru ), Колышев Андрей Сергеевич ( ASkolyishev@bk.ru ).

Журнал «Современная наука: актуальные проблемы теории и практики» 